\title{
Effects of Errors in Genetic Parameter Estimates on Accuracy of Selection Index for Relative Desired Genetic Changes in Pigs
}

\author{
Masahiro SATOH, Chindo HICKS ${ }^{1}$, Kazuo ISHII ${ }^{1}$ \\ and Tsutomu FURUKAWA \\ National Institute of Agrobiological Resources, Tsukuba-shi 305-8602, Japan \\ ${ }^{1}$ National Institute of Animal Industry, Tsukuba Norin Kenkyu Danchi, \\ Ibaraki-ken 305-0901, Japan
}

(Received January 21, 2000 ; Accepted April 21, 2000)

\begin{abstract}
The effects of errors in estimates of genetic parameters on genetic response to selection in pigs were investigated when the selection was based on selection index for relative desired genetic changes (DC-index). The effects of errors on gains based on economic selection index (Smith-Hazel index : SH-index) were also investigated to compare with DC-index. Information on individual phenotype of candidate for selection (SIC) and on family (SIF) of the candidate was used in selection index. Average daily gain (DG), backfat thickness (BF) and litter size at birth (LS) were considered as traits for breeding objective and selection criteria. The respective heritabilities of $0.3,0.5$ and 0.1 for DG, BF and LS, with genetic and phenotypic correlations between DG and BF of 0.2, and no correlations between LS and DG and BF were assumed. A distinction is drawn between the response $\left[E\left(\Delta H_{0}\right)\right]$ possible with use of the optimum index based on exact parameters and that achieved $[\mathrm{E}$ ( $\Delta$ $\left.\mathbf{H}_{1}\right)$ ] with an index which uses the estimates of the genetic parameters in SH-index. We also draw a distinction between the response $\left[\mathrm{E}\left(\Delta \mathrm{g}_{0 i}\right)\right]$ possible with use of the optimum index and that achieved $\left[\mathrm{E}\left(\Delta \mathrm{g}_{\mathrm{i}}\right)\right]$ of each $\mathrm{i}^{\text {th }}$ trait with an index which uses the estimates of the parameters in DC-index. The efficiencies of selection in SH-index and DC-index were defined as $R_{H}\left[=E\left(\Delta H_{1}\right) / E\left(\Delta H_{0}\right)\right]$ and $R_{D}$ [the minimum value of $\mathrm{E}\left(\Delta \mathrm{g}_{1 i}\right) / \mathrm{E}\left(\Delta \mathrm{g}_{0 i}\right)$ in all selected traits], respectively. Errors in estimates of genetic correlation had smaller effect for $R_{H}$ and $R_{D}$ than errors in estimates of heritability per unit. Expected loss in efficiency in DC-index was more sensitive than SH-index to incorrect estimates of heritability or genetic correlation. Errors in phenotypic correlation scarcely affect both $\mathbf{R}_{\mathrm{H}}$ and $\mathbf{R}_{\mathrm{D}}$. For response to selection, the effect of error in estimate of heritability for LS was the largest in three traits. If there is no confirmation of accurate estimates of genetic parameters (e.g. genetic parameters in literature are used in selection programs) and if absolute of relative desired change for LS per genetic standard deviation unit is larger than that for both $\mathrm{DG}$ and $\mathrm{BF}$, a higher heritability for LS should be used to construct selection index.
\end{abstract}

Animal Science Joumal 71 (4) : 363-370, 2000

Key words : Genetic parameters, Error of estimate, Desired change index, Family information, Pigs

Economic selection index ${ }^{6)}$ or multiple-trait best linear unbiased prediction (BLUP) procedures ${ }^{7)}$ is used to evaluate candidates for selection when the breeding objective is to maximize improvement of economic merit. However, the assignment of the economic weights is not always easy in practical situations. Selection index for desired changes has, thus, used to evaluate candidates for selection in Japanese breeding systems for pig strains in a closed herd. The index for relative desired genetic changes ${ }^{2,20)}$ is

Corresponding : Masahiro SATOH (fax : +81 (0) 298-38-7408, e-mail : hereford@abr.affrc.go.jp)

Anim. Sci. J. 71 (4) : 363-370, 2000 


\section{SATOH, HICKS, ISHII and FURUKAWA}

convenient for practical use because they do not require the definition of the economic weights. Recently restricted BLUP ${ }^{12)}$ of breeding values for all traits with relative changes has become widely accepted as a standard method for evaluating pigs in selection programs of a closed herd.

When animals are evaluated based on selection index or BLUP procedures, the population parameters are usually assumed to be known. But in practice the parameters are estimates and may differ from true values. If the base population size is not large, we cannot always estimate the appropriate genetic parameters from the data of base animals, e.g. the estimates may be biased or near the critical values in parameter space. Consequently, if there are errors in parameter estimates, the actual selection response may be suboptimal. Several studies have examined the effects of errors in genetic parameters on the efficiency of onetrait and economic selection indices ${ }^{5,11,14,15)}$ and multitrait BLUP ${ }^{18)}$, but there is little information on the efficiency of index for desired changes or restricted BLUP procedures.

The purpose of this study was to investigate effects of errors in estimated genetic parameters on accuracy and expected response from desired change index. Effects of errors in estimated genetic parameters on gains from economic index were also investigated to compare with gains from index for desired changes. Information on both individual phenotype of candidate for selection and family of the candidate was used in selection index.

\section{Methods}

Let $\mathbf{I}_{0}$ be a linear selection index with $\mathbf{I}_{0}=\mathbf{b}_{0}{ }^{\prime} \mathbf{p}$, where $\mathbf{b}_{0}$ is a vector of weighting factors and $\mathbf{p}$ is a vector of phenotypic observations as deviations from their relevant means. Let $\mathrm{H}_{0}$ be a linear aggregate breeding value with $\mathrm{H}_{0}=\mathbf{a}^{\prime} \mathbf{g}$, where $\mathbf{a}$ is a vector of economic weights and $\mathbf{g}$ is a vector of additive genetic merits of traits. The index weights are given by

$$
\mathbf{b}_{0}=\mathbf{P}_{0}{ }^{-1} \mathbf{G}_{0} \mathbf{a} \text {. }
$$

where $\mathbf{P}_{0}=\operatorname{var}(\mathbf{p})$ and $\mathbf{G}_{0}=\operatorname{cov}\left(\mathbf{p}, \mathbf{g}^{\prime}\right)$. The superiority $\left(\Delta \mathrm{H}_{0}\right)$ in aggregate breeding value of individuals selected in mass selection by an index $\mathbf{I}_{0}$ (in the following abbreviated as SH-index) is

$$
\begin{aligned}
\mathrm{E}\left(\Delta \mathbf{H}_{0}\right) & =\mathrm{i} \sigma_{\mathrm{H}} \mathrm{r}_{\mathrm{IOH}} \\
& =\mathrm{i} \operatorname{cov}\left(\mathbf{b}_{0}{ }^{\prime} \mathbf{p}, \mathbf{g}^{\prime} \mathbf{a}\right)\left(\mathbf{b}_{0}{ }^{\prime} \mathbf{P}_{0} \mathbf{b}_{0}\right)^{-1 / 2} \\
& =\mathrm{i}\left(\mathbf{b}_{0}{ }^{\prime} \mathbf{P}_{0} \mathbf{b}_{0}\right)^{1 / 2},
\end{aligned}
$$

where $i$ is the standardized selection differential, $\sigma_{\mathrm{H}}$ is the standard deviation of $\mathrm{H}$ and $\mathrm{r}_{\mathrm{IOH}}$ is the correlation between $I_{0}$ and $H$. The vector of genetic gains $\left(\Delta g_{0}\right)$ in each trait selected using an index $I_{0}$ is

$$
\begin{aligned}
\mathrm{E}\left(\Delta \mathbf{g}_{0}\right) & =\mathbf{i} \mathbf{G}_{0}{ }^{\prime} \mathbf{b}_{0} / \sigma_{\mathrm{I}} \\
& =\mathbf{i} \mathbf{G}_{0}^{\prime} \mathbf{P}_{0}{ }^{-1} \mathbf{G}_{0} \mathbf{a}\left(\mathbf{b}_{0}{ }^{\prime} \mathbf{P}_{0} \mathbf{b}_{0}\right)^{-1 / 2} .
\end{aligned}
$$

In any practical situation, only estimates for $\mathbf{P}_{0}$ and $\mathbf{G}_{0}$ ( $\hat{\mathbf{P}}_{0}$ and $\hat{\mathbf{G}}_{0}$ ) will be available. The weights of the estimated index $\mathrm{I}_{1}$, are usually taken as,

$$
\mathbf{b}_{1}=\hat{\mathbf{P}}_{0}^{-1} \hat{\mathbf{G}}_{0} \mathbf{a}
$$

and the actual progress achieved using $I_{1}$ is given by

$$
\begin{aligned}
& \mathrm{E}\left(\Delta \mathbf{H}_{1}\right)=\mathrm{i} \operatorname{cov}\left(\mathbf{b}_{1}{ }^{\prime} \mathbf{p}, \mathbf{g}^{\prime} \mathbf{a}\right)\left(\mathbf{b}_{1}{ }^{\prime} \mathbf{P}_{0} \mathbf{b}_{1}\right)^{-1 / 2} \\
& =\mathrm{i} \mathbf{b}_{1}{ }^{\prime} \mathbf{P}_{0} \mathbf{b}_{0}\left(\mathbf{b}_{1}{ }^{\prime} \mathbf{P}_{0} \mathbf{b}_{1}\right)^{-1 / 2} \text {. }
\end{aligned}
$$

Thus the efficiency of selection on $\mathrm{I}_{1}$, relative to selection on $\mathbf{I}_{0}$ is simply,

$$
\begin{aligned}
\mathrm{R}_{\mathrm{H}}= & \mathrm{E}\left(\Delta \mathrm{H}_{1}\right) / \mathrm{E}\left(\Delta \mathrm{H}_{0}\right) \\
= & \mathbf{a}^{\prime} \hat{\mathbf{G}}_{0}{ }^{\prime} \hat{\mathbf{P}}_{0}^{-1} \mathbf{G}_{0} \mathbf{a}\left(\mathbf{a}^{\prime} \hat{\mathbf{G}}_{0}^{\prime} \hat{\mathbf{P}}_{0}^{-1} \mathbf{P}_{0} \hat{\mathbf{P}}_{0}{ }^{-1} \hat{\mathbf{G}}_{0} \mathrm{aa}^{\prime} \mathbf{G}_{0}{ }^{\prime}\right. \\
& \left.\mathbf{P}_{0}{ }^{-1} \mathbf{G}_{0} \mathbf{a}\right)^{-1 / 2} .
\end{aligned}
$$

Secondly, let $I_{2}$ be an index for desired changes with $\mathbf{I}_{2}=\mathbf{b}_{2}{ }^{\prime} \mathbf{p}$, where $\mathbf{b}_{2}$ is a vector of weighting factors. Then,

$$
\mathbf{b}_{2}=\mathbf{P}_{0}{ }^{-1} \mathbf{G}_{0}\left(\mathbf{G}_{0}{ }^{\prime} \mathbf{P}_{0}{ }^{-1} \mathbf{G}_{0}\right)^{-1} \mathbf{d}
$$

where $\mathbf{d}$ is a vector of relative genetic changes for all traits. The vector of genetic gains $\left(\Delta \mathrm{g}_{2}\right)$ in each trait selected using an index $I_{2}$ (abbreviated as DCindex) is

$$
\begin{aligned}
\mathrm{E}\left(\Delta \mathbf{g}_{2}\right) & =\mathbf{i} \mathbf{G}_{0}{ }^{\prime} \mathbf{b}_{2} / \sigma_{\mathrm{I} 2} \\
& =\mathbf{i d}\left[\mathbf{d}^{\prime}\left(\mathbf{G}_{0}{ }^{\prime} \mathbf{P}_{0}{ }^{-1} \mathbf{G}_{0}\right)^{-1} \mathbf{d}\right]^{-1 / 2} .
\end{aligned}
$$

Because $\hat{\mathbf{P}}_{0}$ and $\hat{\mathbf{G}}_{0}$ are available, the index weights of the estimated index $I_{3}$, are taken as,

$$
\mathbf{b}_{3}=\hat{\mathbf{P}}_{0}{ }^{-1} \hat{\mathbf{G}}_{0}\left(\hat{\mathbf{G}}_{0}{ }^{\prime} \hat{\mathbf{P}}_{0}{ }^{-1} \hat{\mathbf{G}}_{0}\right)^{-1} \mathbf{d}
$$

and the vector of actual genetic gains achieved using $\mathbf{I}_{3}$ is given by

$$
\begin{aligned}
\mathrm{E}\left(\Delta \mathbf{g}_{3}\right)= & \mathrm{i} \mathbf{G}_{0}{ }^{\prime} \mathbf{b}_{3} / \sigma_{\mathrm{I} 3} \\
= & \mathrm{i} \mathbf{G}_{0}{ }^{\prime} \hat{\mathbf{P}}_{0}{ }^{-1} \hat{\mathbf{G}}_{0}\left(\hat{\mathbf{G}}_{0}{ }^{\prime} \hat{\mathbf{P}}_{0}{ }^{-1} \hat{\mathbf{G}}_{0}\right)^{-1} \mathbf{d} /\left[\mathbf { d } ^ { \prime } \left(\hat{\mathbf{G}}_{0}{ }^{\prime}\right.\right. \\
& \left.\hat{\mathbf{P}}_{0}{ }^{-1} \hat{\mathbf{G}}_{0}\right)^{-1} \hat{\mathbf{G}}_{0}{ }^{\prime} \hat{\mathbf{P}}_{0}{ }^{-1} \mathbf{P}_{0} \hat{\mathbf{P}}_{0}{ }^{-1} \hat{\mathbf{G}}_{0}\left(\hat{\mathbf{G}}_{0}{ }^{\prime} \hat{\mathbf{P}}_{0}{ }^{-1}\right. \\
& \left.\left.\hat{\mathbf{G}}_{0}\right)^{-1} \mathbf{d}\right]^{-1 / 2} .
\end{aligned}
$$

Let $g_{0 \mathrm{i}}$ and $\mathrm{g}_{1 \mathrm{i}}$ be the $\mathrm{i}^{\text {th }}$ elements of $\mathrm{E}\left(\Delta \mathrm{g}_{2}\right)$ and $\mathrm{E}$ ( $\Delta$ $\mathbf{g}_{3}$ ), respectively. Thus,

$$
\begin{aligned}
R_{D}= & \text { the minimum value of }\left(g_{11} / g_{01}, g_{12} / g_{02}, \cdots,\right. \\
& \left.g_{1 m} / g_{0 n 1}\right)
\end{aligned}
$$

which means one of the efficiency of selection on $\mathrm{I}_{3}$ 
Table 1. Genetic parameters, economic weights and desired changes for average daily gain (DG), backfat thickness (BF) and litter size at birth (LS) in the experiment

\begin{tabular}{lrrrrrrrr}
\multicolumn{1}{c}{ Trait } & $\begin{array}{c}\text { Phenotypic } \\
\text { variance }\end{array}$ & $\mathrm{r}_{\mathrm{G}}$ & $\mathrm{h}^{2}$ & $\mathrm{r}_{\mathrm{p}}{ }^{1)}$ & $\begin{array}{c}\text { Economic } \\
\text { weight }\end{array}$ & \multicolumn{3}{c}{ Desired change $^{2)}$} \\
\hline Daily gain (g/day ; DG) & 7744 & .3 & .2 & .0 & 43 & 48.2 & 48.2 & 48.2 \\
Back fat thickness (mm ; BF) & 4 & .2 & .5 & .0 & -820 & -1.414 & -1.414 & -1.414 \\
Litter size at birth (LS) & 4 & .0 & .0 & .1 & 4086 & 0.3162 & 0.6326 & 1.2649 \\
\hline
\end{tabular}

${ }^{1)}$ Diagonal : heritability $\left(\mathrm{h}^{2}\right)$, above diagonal : phenotypic correlation $\left(\mathrm{r}_{\mathrm{P}}\right)$, below diagonal : genetic correlation $\left(\mathrm{r}_{\mathrm{G}}\right)$.

2) Desired changes were assumed to be one genetic standard deviation unit for DG and BF, and (a) .5 , (b) 1.0 or (c) 2.0 genetic standard deviation unit for LS.

Table 2. Expected genetic changes of average daily gain (DG), back fat thickness (BF) and litter size at birth (LS) based on different selection indices

\begin{tabular}{cccccc}
\hline \multirow{2}{*}{ Index $^{13}$} & \multirow{2}{*}{$\begin{array}{l}\text { Relative } \\
\text { change }^{21}\end{array}$} & $\begin{array}{c}\text { Information } \\
\text { of relatives }\end{array}$ & \multicolumn{3}{c}{ Expected genetic change $^{47}$} \\
\cline { 4 - 6 } & - & DG (g/day) & BF (mm) & LS \\
\hline SH & $2: 2: 1$ & SIC & 19.3 & -.44 & .03 \\
DC & SIF & 24.1 & -.41 & .07 \\
& & SIC & 11.8 & -.35 & .08 \\
& SIF & 16.8 & -.49 & .11 \\
& $1: 1: 1$ & SIC & 7.1 & -.21 & .09 \\
& & SIF & 11.1 & -.33 & .15 \\
& $1: 1: 2$ & SIC & 3.7 & -.11 & .10 \\
& & SIF & 6.2 & -.18 & .16 \\
\hline
\end{tabular}

\footnotetext{
${ }^{1} \mathrm{SH}:$ Economic selection index, $\mathrm{DC}$ : selection index for desired changes.

2) Relative desired change of DG : BF : LS.

${ }^{3)}$ SIC : DG and BF of candidate for selection and of LS of dam, SIF : family selection index.

${ }^{4)}$ Standardized selection intensity was assumed to be 1.0 .
}

relative to selection on $I_{2}$, where $m$ is the number of traits for desired changes.

The breeding objective was to improve $\mathrm{DG}, \mathrm{BF}$ and LS by maximizing aggregate breeding value or achieving predetermined relative changes for all traits. $R_{H}$ and $R_{D}$ were computed using information on $(1)$ the candidate for DG and $\mathrm{BF}$ and the candidate's dam for LS (selection index based on candidate for selection, SIC) and (2) candidate for selection, its parents and grand parents, and their full and half sibs (family) for DG and BF, and all females in family excluding candidate's generation for LS (selection index based on family information ${ }^{1}$, SIF). The latter was used to estimate breeding values based on an animal model BLUP or that with restrictions ${ }^{177}$. A mating ratio of 10 females per male was assumed and the considered number of sibs per litter for the breeding stock was two (one male and one female). As a result, a candidate for selection has six animals as direct ancestors with records for the breeding traits and each animal has one full sib and 18 half sibs, consequently, the order of $b_{i}(i=1,2,3$ and 4$)$ is a $(340 \times 1)$ vector.

In evaluating and comparing the different selection strategies, a standard set of genetic parameters, economic weights and desired changes used in index calculations are presented in Table 1. Economic 
weights were quoted from a paper by $\operatorname{Ieiri}^{8)}$. The deviations of estimated heritability $\left(\hat{\mathrm{h}}^{2}\right)$ from the true heritability $\left(\mathrm{h}^{2}\right)$ were assumed to be $-0.09,-0.08$, $\cdots \cdots, 0.09$, and the deviations of estimated genetic $\left(\hat{\mathrm{r}}_{\mathrm{G}}\right)$ and phenotypic $\left(\hat{\mathrm{r}}_{\mathrm{P}}\right)$ correlations from true correlations $\left(r_{G}\right.$ and $\left.r_{P}\right)$ were assumed to be $-0.20,-0.19$, $\cdots \cdots, 0.20$, and $-0.10,-0.09, \cdots \cdots, 0.10$, respectively. $\mathbf{R}_{H}$ and $R_{D}$ were calculated using $\hat{\mathrm{h}}^{2}, \hat{\mathbf{r}}_{\mathrm{G}}$ and $\hat{\mathrm{r}}_{\mathrm{P}}$. Secondly, $h^{2}$ and $r_{G}$ with errors in Table 1 were assumed as true heritability and genetic correlation, respectively.

\section{Results and Discussion}

Table 2 shows $\mathrm{E}\left(\Delta \mathrm{g}_{0}\right)$ and $\mathrm{E}\left(\Delta \mathrm{g}_{2}\right)$ of $\mathrm{DG}, \mathrm{BF}$ and LS. Expected genetic gains of DG, BF and LS using SIF for SH-index were $25 \%,-6 \%$ and $126 \%$ larger than those using SIC. E ( $\left.\Delta \mathrm{H}_{0}\right)$ using SIF was 1.26 times larger than that using SIC. For DC-index, selection using SIF was about 1.5 times larger than expected genetic gain of each trait using SIC. Results of selection indices using SIF show approximate estimated breeding values based on an animal model BLUP in a closed herd of pigs ${ }^{16,17)}$. Hence utilization of the family information, especially for DC-index, is effective for genetic evaluation in pigs.

Figure $1 \mathrm{a}, 1 \mathrm{~b}$ and $1 \mathrm{c}$ illustrate $\mathrm{R}_{\mathrm{H}}$ for $\mathrm{SH}$-index with the different values of $\hat{\mathrm{h}}^{2}, \hat{\mathrm{r}}_{\mathrm{G}}$ and $\hat{\mathrm{r}}_{\mathrm{P}}$, respectively, where the true genetic parameters are assumed to be those in Table 1. $R_{H}$ decreased rapidly with increasing $\left|h^{2}-\hat{h}^{2}\right|$ for LS, but hardly decreased for BF. The changes in $\hat{\mathbf{r}}_{\mathrm{P}}$ scarcely affect $\mathbf{R}_{\mathrm{H}}$. Underestimate of heritability $\left(h^{2}<\hat{h}^{2}\right)$ had larger $R_{H}$ than overestimate of that $\left(\hat{h}^{2}<h^{2}\right)$ in each trait. Underestimate of genetic correlation, however, had smaller $\mathbf{R}_{\mathrm{H}}$ than overestimate of that in each trait. The estimated error in $\mathbf{r}_{G}$ had smaller effect than that in $h^{2}$ per unit. Accuracy of estimating heritability for LS was the most important to estimate the aggregate breeding value.

Figure 2 shows $\mathbf{R}_{D}$ for $\mathrm{DC}$-index with the different values of $\hat{h}^{2}$ and $\hat{\mathbf{r}}_{\mathrm{G}}$ when relative desired changes of $\mathrm{DG}, \mathrm{BF}$ and $\mathrm{LS}$ are $2: 2: 1,1: 1: 1$ and $1: 1: 2$, respectively. Because the effect of error of $r_{P}$ was very small for DC-index as well as SH-index, the figures were omitted. The $\mathrm{R}_{\mathrm{D}}$ increased gradually as
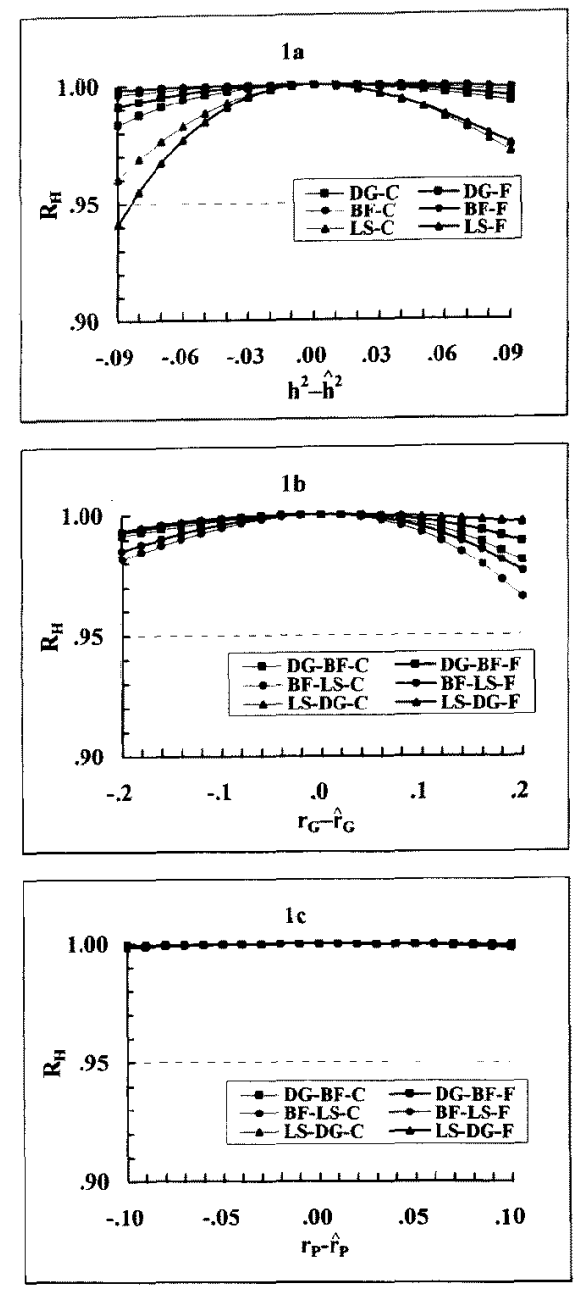

Fig. 1. $\mathrm{R}_{\mathrm{H}}$ for economic selection index (SHindex) with the different estimates of heritabilities (1 a) with average daily gain (DG), backfat thickness (BF) and litter size at birth (LS), and the genetic ( $1 \mathrm{~b}$ ) and phenotypic correlations (1c) between them. In legends letters $\mathrm{C}$ and $\mathrm{F}$ indicate index selection using information on candidate for selection and using family information, respectively.

the relative desired change for LS increased when heritability for LS was overestimated, or heritability for $\mathrm{DG}$ or $\mathrm{BF}$ was underestimated. On the other hand, the $R_{D}$ decreased as the desired change for $L S$ increased in the case of underestimated heritability for LS, or overestimated that for DG or BF. The efficiency of DC-index was more sensitive than SH-index to incorrect genetic parameters, particularly for 

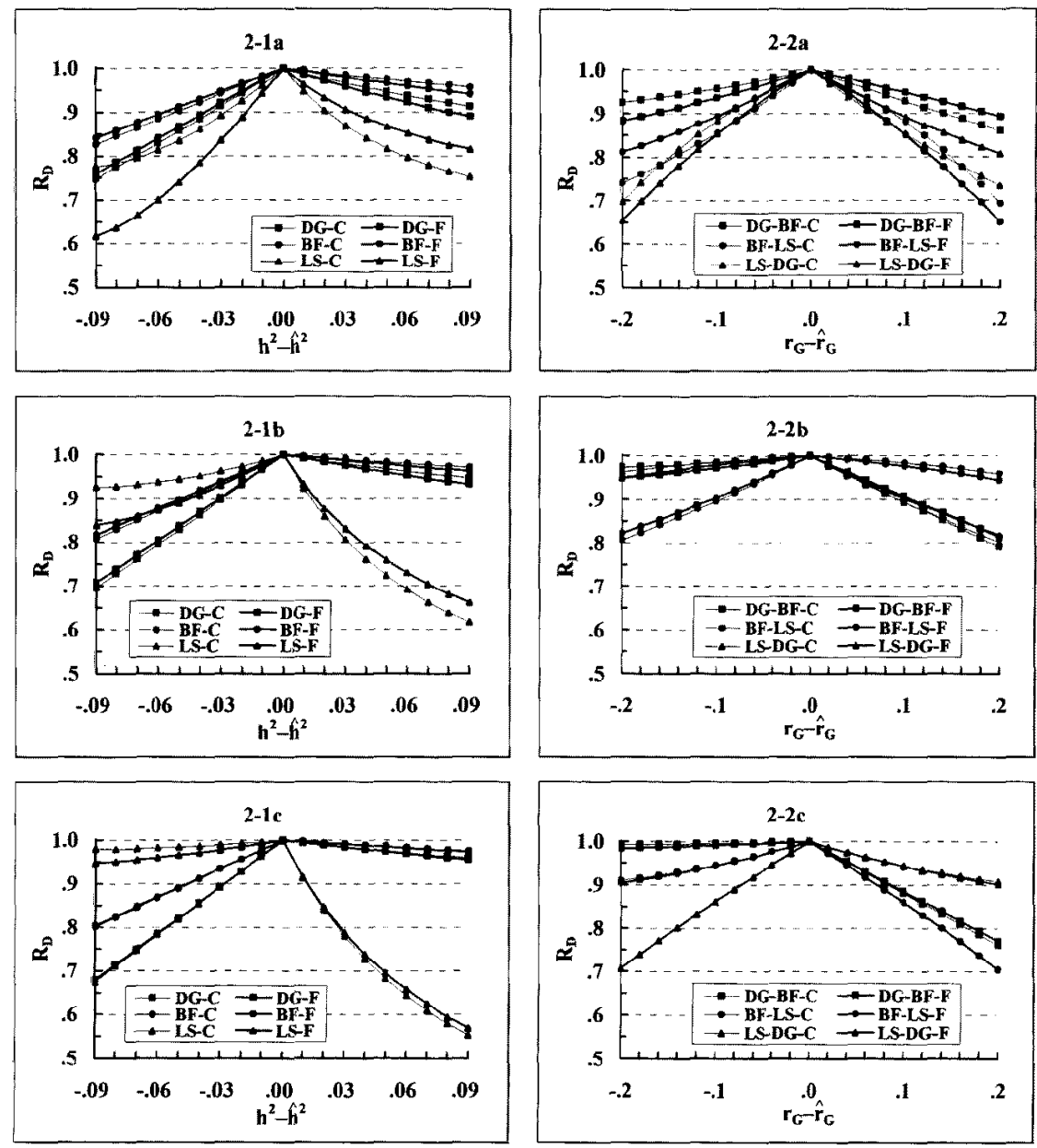

Fig. 2. $\mathrm{R}_{\mathrm{D}}$ selection index for relative desired changes (DC-index) with the different estimates of heritabilities (2-1) with average daily gain (DG), backfat thickness (BF) and litter size at birth (LS), and the genetic correlations (2-2) between them when relative desired change of DG, BF and LS were $2: 2: 1$ (a), $1: 1: 1$ (b) and $1: 1: 2$ (c), respectively. In legends letters $C$ can $F$ indicate index selection using information on candidate for selection and using family information, respectively.

heritability of LS or genetic correlations between LS, and DG or BF.

Table 3 shows expected loss in efficiency for SHindex and DC-index with different estimates of heritability. The expected loss in efficiency was defined as $1-\mathrm{R}_{\mathrm{H}}$ for $\mathrm{SH}$-index and $1-\mathrm{R}_{\mathrm{D}}$ for $\mathrm{DC}$-index, respectively. The expected loss decreased with increasing $h^{2}$ except for LS in DC-index when the difference between $h^{2}$ and $\hat{h}^{2}$ was constant. For error in heritability DC-index was less efficient than SH-index. Table 4 shows expected loss in efficiency for SH-index and
DC-index with the different estimates of genetic correlation. The expected loss in efficiency increased with increasing $r_{G}$ between $D G$ and $B F$, or BF and LS when the difference between $\mathbf{r}_{G}$ and $\hat{r}_{G}$ was constant. The efficiency of DC-index was more sensitive than that of SH-index with errors of genetic parameter estimates.

Pigs in a closed herd have mainly been selected for both increasing DG and reducing BF. Recently LS has been considered as a trait for breeding objective and selection in dam lines because the application of 


\section{SATOH, HICKS, ISHII and FURUKAWA}

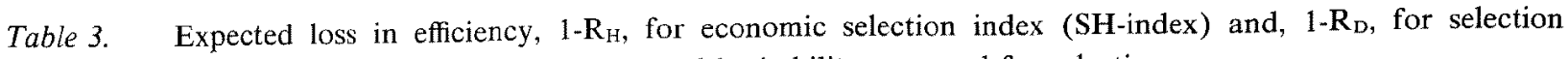
index for desired changes (DC-index) when assumed heritability was used for selection

\begin{tabular}{|c|c|c|c|c|c|c|c|c|c|c|c|}
\hline \multirow{2}{*}{ Index } & \multirow{2}{*}{$\begin{array}{l}\text { Information } \\
\text { of relatives }^{\text {s) }}\end{array}$} & \multirow{2}{*}{$h^{2}-\hat{h}^{2 b}$} & \multicolumn{3}{|c|}{$\mathrm{h}^{2}$ of average daily gain } & \multicolumn{3}{|c|}{$\mathrm{h}^{2}$ of backfat thickness } & \multicolumn{3}{|c|}{$\mathrm{h}^{2}$ of litter size at birth } \\
\hline & & & .25 & .30 & .35 & .45 & .50 & .55 & .05 & .10 & .15 \\
\hline \multirow[t]{8}{*}{ SH } & SIC & -.10 & .033 & .021 & .014 & .005 & .004 & .004 & & & .043 \\
\hline & & -.05 & .004 & .003 & .002 & .001 & .001 & .001 & & .012 & .010 \\
\hline & & +.05 & .004 & .003 & .002 & .001 & .001 & .001 & .012 & .010 & .008 \\
\hline & & +.10 & .014 & .009 & .006 & .004 & .004 & .003 & .043 & .034 & .026 \\
\hline & SIF & -.10 & .015 & .010 & .008 & .002 & .002 & .002 & & & .052 \\
\hline & & -.05 & .003 & .002 & .002 & .000 & .000 & .000 & & .016 & .009 \\
\hline & & +.05 & .002 & .002 & .002 & .000 & .000 & .000 & .015 & .009 & .006 \\
\hline & & +.10 & .009 & .007 & .006 & .002 & .002 & .002 & .047 & .029 & .018 \\
\hline \multirow[t]{8}{*}{$\mathrm{DC}$} & SIC & -.10 & .182 & .115 & .079 & .058 & .047 & .038 & & & .617 \\
\hline & & -.05 & .067 & .045 & .032 & .025 & .020 & .017 & & .471 & .276 \\
\hline & & +.05 & .171 & .151 & .135 & .107 & .098 & 091 & .056 & .079 & .092 \\
\hline & & +.10 & .299 & .268 & .243 & .196 & .181 & 169 & .130 & .164 & .180 \\
\hline & SIF & -.10 & .217 & .143 & .101 & .076 & .061 & .050 & & & .583 \\
\hline & & -.05 & .081 & .056 & .041 & .033 & .027 & .022 & & .445 & .241 \\
\hline & & +.05 & .163 & .145 & .130 & .102 & .094 & .087 & .110 & .130 & .130 \\
\hline & & +.10 & .288 & .259 & .235 & .188 & .175 & .163 & .233 & .248 & .242 \\
\hline
\end{tabular}

${ }^{2}$ SIC : Average daily gain and backbat thickness of candidate for selection and of litter size at birth of dam ; SIF : family selection index.

b) The difference between real and assumed heritabilities.

BLUP procedure to genetic evaluation gives the greatest benefit in selection for traits of low heritability. Although the genetic parameters used in the present study may not always apply to all pig populations, the estimates for DG, BF and LS were similar to those reported in most previous studies ${ }^{3,4,9,10,13 \text { ). }}$

Family selection indices ${ }^{1 /}$ were used to estimate the effects of selection based on BLUP in the present study. In general we cannot estimate breeding values using a family selection index from actual data because of different amounts of information from relatives. However family selection index is an effective tool for estimating the response to selection using BLUP and constructing the breeding plan in a closed herd of pigs ${ }^{17)}$. From the results of this study, the effect of error in heritability estimate for LS was the largest when the breeding objective was to improve DG, BF and LS. Smith ${ }^{19)}$ suggested that the efficien- cy of selection index was sensitive to loss of weight for the originally important trait which dominated the index as measured by the product of the economic weight and the heritability for the trait. It means that the efficiency is sensitive to error of estimated genetic variance for the important trait.

Recently, genetic parameters have usually been estimated by Restricted maximum likelihood (REML) procedure. Particularly multivariate animal model REML can give accurate estimates of genetic parameters. However, if genetic parameters are estimated by the data from the small population, they may be biased. When there is no confirmation of accurate estimates of genetic parameters, genetic parameters in literature are generally used in selection programs in a closed herd of pigs. In that case, higher heritability for LS should be used to construct selection index if relative desired change for LS per genetic standard 
Table 4. Expected loss in efficiency, 1-R $\mathrm{R}_{\mathrm{H}}$, for economic selection index (SH-index) and, $1-\mathrm{R}_{\mathrm{D}}$, for selection index of desired changes (DC-index) when assumed genetic correlation was used for selection

\begin{tabular}{|c|c|c|c|c|c|c|c|c|c|c|c|}
\hline \multirow{2}{*}{ Index } & \multirow{2}{*}{$\begin{array}{l}\text { Information } \\
\text { of relatives }\end{array}$} & \multirow{2}{*}{$\left.\mathrm{r}_{G}-\hat{\mathrm{r}}_{\mathrm{G}} \mathrm{b}\right)$} & \multicolumn{3}{|c|}{$\mathrm{r}_{\mathrm{G}}$ between $\mathrm{DG}$ and $\mathrm{BF}^{\mathrm{c}}$} & \multicolumn{3}{|c|}{$\mathrm{r}_{\mathrm{G}}$ between $\mathrm{BF}$ and $\mathrm{LS}^{\mathrm{c})}$} & \multicolumn{3}{|c|}{$\mathbf{r}_{\mathrm{G}}$ between $\mathrm{LS}$ and $\mathrm{DG}^{\mathrm{v}}$} \\
\hline & & & .10 & .20 & .30 & -.10 & .00 & .10 & -.10 & .00 & .10 \\
\hline \multirow[t]{8}{*}{ SH } & SIC & -.20 & .006 & .008 & .013 & .013 & .019 & .026 & .010 & .007 & .004 \\
\hline & & -.10 & .002 & .002 & .004 & .004 & .005 & .007 & .002 & .001 & .001 \\
\hline & & +.10 & .002 & .004 & .006 & .005 & .007 & .010 & .001 & .001 & .001 \\
\hline & & +.20 & .013 & .019 & .030 & .025 & .034 & .134 & .004 & .003 & .002 \\
\hline & SIF & -.20 & .007 & .008 & .009 & .012 & .015 & .019 & .009 & .006 & .005 \\
\hline & & -.10 & .002 & .002 & .002 & .003 & .004 & .005 & .002 & .001 & .001 \\
\hline & & +.10 & .002 & .002 & .002 & .004 & .005 & .006 & .001 & .001 & .003 \\
\hline & & +.20 & .008 & .010 & .013 & .018 & .023 & .029 & .005 & .008 & .003 \\
\hline \multirow[t]{8}{*}{$\mathrm{DC}$} & SIC & -.20 & .166 & .179 & .193 & .023 & .030 & .036 & .242 & .222 & .207 \\
\hline & & -.10 & .090 & .097 & .106 & .010 & .014 & .016 & .123 & .113 & .106 \\
\hline & & +.10 & .015 & .021 & .031 & .104 & .111 & .120 & .014 & .011 & .007 \\
\hline & & +.20 & .036 & .052 & .077 & .203 & .218 & .238 & .030 & .021 & .016 \\
\hline & SIF & -.20 & .151 & .162 & .173 & .048 & .051 & .054 & .234 & .212 & .195 \\
\hline & & -.10 & .081 & .087 & .093 & .021 & .023 & .024 & .117 & .107 & .099 \\
\hline & & +.10 & 028 & .037 & .050 & .096 & .104 & .115 & .021 & .020 & .018 \\
\hline & & +.20 & .067 & .088 & .120 & .191 & 208 & .230 & .048 & .045 & .042 \\
\hline
\end{tabular}

a) SIC : DG and BF of candidate for selection and of LS of dam ; SIF : family selection index.

b) The difference between real and assumed genetic correlations.

${ }^{\circ}$ DG : average daily gain, BF : backfat thickness, LS : litter size at birth.

deviation unit is larger than that for $\mathrm{DG}$ and $\mathrm{BF}$.

\section{References}

1) Avalos E, Smith C. Genetic improvement of litter size in pigs. Animal Production, 44 : 153-164. 1987.

2) Brascamp EW. Selection indices with constraints. Animal Breeding Abstract, 52:645-654. 1984.

3) Ducos A, Bidanel JP, Ducrocq V, Boichard D, Groeneveld E. Multivatiate restricted maximum likelihood estimation of genetic parameters for growth, carcass and meat quality traits in French Large White and French Landrace pigs. Genetics Selection Evolution, 25: 475-493. 1993.

4) Haley CS, Lee GJ. Genetic factors contributing to variation in litter size in British Large White gilts. Livestock Production Science, 30 : 99-113. 1992.

5) Hayes JE, Hill WG. Modification of estimates of parameters in the construction of genetic selection indices ('bending'). Biometrics, $37: 483-493.1981$.
6) Hazel LN. The genetic basis for constructing selection indexes. Genetics, $28: 476-490.1943$.

7) Henderson CR, Quaas RL. Multiple trait evaluation using relatives' records. Journal of Animal Science, $43: 1188-1197.1976$.

8) Ieiri S. Estimation of economic values on days to market and carcass traits in pig breeding. Japanese Journal of Swine Science, $31: 1-7.1994$.

9) Li X, Kennedy BW. Genetic parameters for growth rate and backfat in Canadian Yorkshire, Landrace, Duroc and Hampshire pigs. Journal of Animal Science, $72: 1450-1454.1994$.

10) Lo LL, McLaren DG, McKeith FK, Fernando RL, Novakofski J. Genetic analyses of growth, real-time ultrasound, carcass, and pork quality traits in Duroc and Landrace pigs: II. Heritabilities and correlations. Journal of Animal Science, $70: 2387-2396$. 1992.

11) Meyer K, Hill WG. A note on the effects of sampling

Anim. Sci. J. 71 (4) : 363-370, 2000 


\section{SATOH, HICKS, ISHII and FURUKAWA}

errors on the accuracy of genetic selection indices. Zeitschrift fur Tierzuchtung und Zuchtungsbiologie, $100: 27-32.1983$.

12) Quass RL, Henderson CR. Restricted Best Linear Unbiased Prediction of Breeding Values. 1-14. Cornell Univ. Press. Mimeo. 1976.

13) Roehe R, Kennedy BW. Estimation of genetic parameters for litter size in Canadian Yorkshire and Landrace swine with each parity of farrowing treated as a different trait. Journal of Animal Science, 73 : 2959-2970. 1995.

14) Sales J, Hill WG. Effect of sampling errors on efficiency of selection indices. 1 use of information from relatives for single trait improvement. Animal Production, $22: 1-17.1976$.

15) Sales J, Hill WG. Effect of sampling errors on efficiency of selection indices. 2 use of information on associated traits for improvement of a single important trait. Animal Production, $23: 1-14.1976$.
16) Satoh M, Furukawa T, Ishii K. Expected genetic gains from desired change index in selection for increased litter size in a closed swine herd. Japanese Journal of Swine Science, 36:13-17. 1999.

17) Satoh M, Hicks C, Ishii K, Furukawa T. Prediction of response to selection based on BLUP of breeding values by expected response to family index selection supporting pig selection program. Animal Science Journal, $71: 17-25.2000$

18) Schaeffer LR. Sire and cow evaluation under multiple trait models. Journal of Dairy Science, $67: 1567^{-}$ 1580. 1984.

19) Smith C. Effects of changes in economic weights on the efficiency of index selection. Journal of Animal Science, 56 : 1057-1064. 1983.

20) Yamada $Y$, Yokouchi $K$, Nishida A. Selection index when genetic gains of individual traits are of primary concern. Japanese Journal of Genetics, $50: 33-41$. 1974. 